\title{
Discharge of Raphe Magnus ON and OFF Cells Is Predictive of the Motor Facilitation Evoked by Repeated Laser Stimulation
}

\author{
H. Foo and Peggy Mason \\ Department of Neurobiology, Pharmacology and Physiology, and Committee on Neurobiology, University of Chicago, Chicago, Illinois 60637
}

Medullary raphe magnus (RM) on and off cells are thought to modulate spinal nociception by gating withdrawals evoked by noxious stimulation. To test whether withdrawal initiation is the target of RM modulation, we examined the relationship between on and ofF cell discharge and motor withdrawal evoked by noxious laser heat in halothane-anesthetized rats. The cellular responses of both cell types began during the $50 \mathrm{msec}$ after onset of the tail flick, peaked within $200 \mathrm{msec}$, and outlasted the duration of the motor reaction. Thus, it is unlikely that the target of on and ofF cell modulation is withdrawal initiation; instead, on and off cells may modulate reactions to repeated noxious stimulation. We therefore tested whether laser heat-evoked changes in RM cell discharge were predictive of the modulatory effects of one noxious stimulus on the reaction to a subsequent noxious stimulus. Two pulses of laser heat were presented at interpulse intervals of $0.8,2.0$, or $10.0 \mathrm{sec}$. The motor withdrawal evoked by the second pulse was significantly enhanced relative to that evoked by the first pulse. The observed motor enhancement depended on supraspinal input because it was not present in spinalized rats. Comparison of the relative changes in motor and cellular activity preceding double laser heat stimulation revealed parallel changes between motor facilitation, decreases in ofF cell discharge, and increases in on cell discharge. This finding suggests a preparatory role for $\mathrm{RM}$ on and ofF cells in enhancing reactions to a noxious stimulus that closely follows another noxious stimulus.

Key words: pain; $\mathrm{CO}_{2}$ laser; motor facilitation; rats; ventromedial medulla; electrophysiology

\section{Introduction}

Neurons in the medullary raphe magnus and adjacent nucleus reticularis magnocellularis (collectively termed RM here) project to the spinal dorsal horn and modulate nociceptive transmission (Fields et al., 1983; Basbaum and Fields, 1984; Sandkuhler and Gebhart, 1984; Mason, 2001). Stimulation and lesion experiments demonstrate that RM has two distinct neuronal populations that mediate opposing nociceptive modulatory functions. Electrophysiological experiments have identified two RM physiological cell classes-ON and OFF cells-that are putatively nociceptive-facilitating and nociceptive-inhibiting, respectively. OFF cells are inhibited by noxious stimulation and excited by opioids, whereas on cells are excited by noxious stimulation and inhibited by opioids. Both cell types are nonserotonergic (Potrebic et al., 1994; Mason, 1997; Gao and Mason, 2000).

Early physiological findings led to the proposal that RM ON and off cells gate noxious stimulus-evoked motor withdrawals (Fields et al., 1983). First, the cellular changes in response to slow-ramping (3-10 sec), noxious tail heat were originally reported to occur before motor withdrawal of the tail, a reaction commonly referred to as a tail flick (Carstens and Wilson, 1993). Second, the reduction in off cell discharge had a steeper slope when aligned to the tail flick than to the thermal stimulus. Findings inconsistent with ON and OFF cells controlling the initiation of motor withdrawal from noxious heat include the following: (1) ON and OFF cells often respond to noxious heat after the onset of a motor reaction; (2) heat-evoked motor withdrawals occur in the

Received Aug. 12, 2002; revised Dec. 10, 2002; accepted Dec. 11, 2002.

This research was supported by the National Institute of Mental Health (R01 MH-60291).

Correspondence should be addressed to Peggy Mason, Department of Neurobiology, Pharmacology and Physiology, University of Chicago, MC 0926, 947 East 58th Street, Chicago, IL 60637. E-mail: p-mason@uchicago.edu. Copyright $\odot 2003$ Society for Neuroscience $\quad 0270-6474 / 03 / 231933-08 \$ 15.00 / 0$ absence of significant changes in the discharge of RM ON and OFF cells; (3) when a large sample of cells was studied, on and off cell responses showed the same slope when averaged with respect to either the onset of the motor withdrawal or the heat stimulus; and (4) most of the cellular response occurs after the initiation of the motor withdrawal (Leung and Mason, 1998). The present study compares the timing of RM cellular responses and the motor reaction evoked by a laser heat stimulus. Precise latency determination can be made using laser stimulation because the skin is heated in a short time ( $\leq 150 \mathrm{msec}$ ), thereby producing nearly synchronous activation of peripheral afferents (Mor and Carmon, 1975; Le Bars et al., 2001).

Because the duration of the cellular response outlasts the motor reaction to noxious stimulation, ON and OFF cells may play an important role in preparing an organism to react to successive noxious stimuli, augmenting the reaction to a second noxious stimulus presented during the cellular responses-OFF cell pause and on cell burst - evoked by a first stimulus. The present experiment tested this hypothesis by comparing the relative changes in cellular and motor responses evoked by double laser pulse stimulation given at different intervals. At short interpulse intervals, when ON and OFF cellular responses are at near peak values, motor facilitation is predicted. In contrast, with long intervals, the cellular response to the first stimulus is likely to be essentially over at the time of the second heat stimulus, and no motor facilitation is predicted.

\section{Materials and Methods}

Surgical preparation

All procedures were reviewed and approved by the University of Chicago Animal Use and Care Committee. Male Sprague Dawley rats (250-400 gm; Charles River, Wilmington, MA) were anesthetized with $1.8-2.0 \%$ halothane via a nose cone. They were placed in a standard stereotaxic 
apparatus and on top of a water-perfused heating pad that maintained their core temperature at $37.0-37.5^{\circ} \mathrm{C}$. A small craniotomy was performed for the introduction of recording microelectrodes. Electromyographic (EMG) electrodes were placed transcutaneously in the paraspinous muscles to record the tail flick (Grossman et al., 1982).

\section{Experimental protocol}

When surgical preparation was complete, halothane concentration was reduced to $0.5-1.0 \%$. Thirty minutes was allowed to reach alveolar equilibrium before a tungsten electrode ( $5 \mathrm{M} \Omega$; A-M Systems, Carlsborg, WA) was introduced into the RM ( -10.3 to $-11.9 \mathrm{~mm}$ from bregma, lateral $0.0-1.0 \mathrm{~mm}$, ventral $8.5-10.5 \mathrm{~mm}$ from cerebellar surface). Extracellular units that were isolated and had a signal-to-noise ratio of $\geq 4$ were studied. Spontaneous background discharge for each unit was recorded for $15 \mathrm{~min}$ in the absence of stimulation. We focused on nonserotonergic neurons because their physiology suggests that they play a role in phasic modulation of nociceptive transmission (Leung and Mason, 1998). Because all available evidence suggests that serotonergic neurons are important exclusively or primarily in the tonic modulation of nociceptive transmission, we did not study serotonergic cells (Mason and Gao, 1998). Therefore, cells that discharged at rates $<3 \mathrm{~Hz}$ and with obvious regularity, i.e., cells that are very likely to be serotonergic, were not studied further. All other cells were tested with a brief $(<1 \mathrm{sec})$ pinch of a hindpaw or the tail. Extracellular units that were either excited or inhibited by this pinch stimulus were studied. The neuronal response to noxious heat was assessed using a $\mathrm{CO}_{2}$ laser similar to the one described by Mor and Carmon (1975). The laser stimulus was a brief fixed pulse $(140-150 \mathrm{msec}, 5 \mathrm{~W})$ that heated a very small $(\sim 1.0 \mathrm{~mm}$ diameter $)$ spot of skin at an average of $>75.0^{\circ} \mathrm{C} / \mathrm{sec}$ (Haimi-Cohen et al., 1983). Single (140 or $150 \mathrm{msec}$ ) and double (140 msec each) pulses of $\mathrm{CO}_{2}$ laser heat were applied to the middle portion of the tail, $6-7 \mathrm{~cm}$ from the tip.

As stated above, we wanted to use interpulse intervals such that the second laser pulse would occur when on and off cellular responses evoked by the first pulse were at near-peak values, at moderately recovered values, and when essentially over. Using data from early experiments on the cellular responses to single pulse stimulation, we estimated that the peak response of on and off cells occurred, on average, $\sim 800$ $\mathrm{msec}$ after the first laser pulse. We further estimated that the responses of ON and OFF cells to the first pulse were moderately recovered by 2 sec after the first laser pulse and nearly completely recovered by $10 \mathrm{sec}$. As seen in Figure 6, these estimates were essentially accurate. For instance, the average on cell response to the first pulse peaked just before the second laser pulse at an interval of $800 \mathrm{msec}$ (see Fig. 6A), whereas on cell discharge was at near-baseline values $10 \mathrm{sec}$ after the first laser pulse (see Fig. 6C).

Single or double laser heat stimuli were presented at intervals of $\geq 3$ min. After physiological characterization, the recording site was marked by applying $20 \mu \mathrm{A}$ anodal current for $4 \mathrm{~min}$.

Data were acquired onto a computer attached to a Power1401 analogto-digital converter. The EMG was acquired at $1 \mathrm{kHz}$. For each isolated unit, a threshold was set using Spike2 acquisition software (CED, Cambridge, UK). When the signal crossed this threshold, the time of that crossing was stored. In addition, 60 digitized points were collected at 20 $\mathrm{kHz}$ and written to file. Saved points included 20 points before and 40 points after threshold crossing. Individual waveforms were reviewed offline and assigned to a particular unit using a template-matching algorithm provided by Spike2.

\section{Surgical and experimental protocol in spinalized rats}

Rats $(n=3)$ were anesthetized with $1.8-2.0 \%$ halothane via a nose cone. The spinal cord was exposed by laminectomy and transected at the $T_{5}-T_{6}$ level with a thermal cautery unit (Geiger Medical Technologies, Monarch Beach, CA). Because of the sagittal bifurcation of primary afferents destined for the dorsal horn, spinal transection produces a complete sensory deficit caudal to the transection as well as a partial deficit in the dermatomes subserved by segments just rostral to the transection. The transections that we made were placed at the rostral end of the surgical exposure, thereby minimizing the area with only partial anesthesia. Gelfoam was placed around the transected cord, and the wound was closed. Anesthesia was discontinued, and the rats were allowed at least $4 \mathrm{hr}$ to recover. During this recovery period, animals received fluids (10 cc Ringer's) but no other drugs. Spinalized animals showed no signs of pain or distress as they ambulated (with their front legs), ate, drank, and groomed in their cages. They were tested in the awake state because withdrawal reflexes are difficult to obtain in anesthetized, spinalized rats (Schouenborg et al., 1992). The rats were restrained in a holder and tested for EMG reactions to double pulses of laser heat presented at 0.8, 2.0, and $10.0 \mathrm{sec}$ interpulse intervals.

\section{Histological processing}

All rats were overdosed with sodium pentobarbital (intraperitoneally) and perfused with a fixative containing $10 \%$ formalin in $0.1 \mathrm{M} \mathrm{PBS}, \mathrm{pH}$ 7.4. The brainstem or spinal cord was removed and placed in $30 \%$ sucrose. Serial coronal sections $(40 \mu \mathrm{m})$ were cut on a freezing microtome, mounted on gelatin-coated slides, and stained with cresyl violet. Recording sites in the brain were examined microscopically and plotted onto standard sections. Spinal sections were examined microscopically to confirm the level of transection.

\section{Analyses}

Cell classification. Although cells with slow and regular discharge that are highly likely to be serotonergic (Mason, 1997; Li and Bayliss, 1998; Wang et al., 2001) were not studied, an algorithm that physiologically identifies serotonergic and nonserotonergic cells was used to ensure that all studied cells were nonserotonergic. Thus, for each cell, the mean $(x), \mathrm{SD}\left(S D_{\mathrm{ISI}}\right)$, and coefficient of variation $\left(C V_{\text {ISI }}\right)$ of the interspike interval were calculated from a $15 \mathrm{~min}$ record of background activity. The function, $y(x$, $\left.S D_{\text {ISI }}\right)=146-x+0.98 S D_{\text {ISI }}$, was then used to physiologically classify cells as serotonergic or nonserotonergic on the basis of the rate and variability of the background cellular discharge (Mason, 1997). Cells with a function value $<0$ were classified as serotonergic, and cells with a function value $>0$ were classified as nonserotonergic. The accuracy of this classification system is $>90 \%$ (Mason, 2001).

All cells were further characterized by their responses to laser heat stimulation of the tail using a quantitative method that has previously been described in detail and validated (Leung and Mason, 1998). Briefly, the variability in background discharge was first quantified as the SD of change across $2 \mathrm{sec}$ bins normalized to impulses per second $\left(S D_{2 \mathrm{sec}}\right)$. The responses to single and double laser pulses were calculated as the difference in unit firing rates (impulses per second) for 2 sec periods before and after the first stimulus. Poststimulus firing was considered to be the amount of firing in $2 \mathrm{sec}$ blocks, commencing $0.5 \mathrm{sec}$ after the first heat stimulus. Heat-evoked decreases in discharge that were $>2 \times S D_{2}$ sec were considered inhibitory responses, and heat-evoked increases in discharge that were $>2 \times S D_{2 \text { sec }}$ were considered excitatory responses. This method provides confidence at $p<0.05$ level that the response evoked by a stimulus on any single trial is unlikely to have occurred spontaneously. The percentage of inhibitory and excitatory responses to tail heat stimulation were calculated for each cell and for each type of stimulus (single pulse, double pulses at $0.8,2.0$, and $10 \mathrm{sec}$ interpulse intervals). Cells inhibited by a majority of heat applications were considered inhibitory, whereas cells excited by a majority of heat applications were considered excitatory. Using this criterion, the probability of a set of responses occurring by chance is very small. For example, the probability of a cell responding to four or five heat trials by chance would be $7 \times 10^{-4}$.

The above analysis was repeated for each response period. The duration of the response of a cell was then defined as the number of sequential response periods in which the cell was inhibited or excited. It is worth noting that this analysis is likely to underestimate the length of time that the discharge of a cell differs significantly from baseline values because (1) it requires a change that is sustained for $2 \mathrm{sec}$ and (2) the threshold for significance is set very stringently (see above example).

Onset and peak of cellular responses to single laser pulses. Both individual and population histograms (bin size: $50 \mathrm{msec}$ ) were used to determine the timing of the cellular response to a single laser pulse with respect to the onset of the tail flick. First, onset and peak responses were determined from individual histograms. The individual onset latency was defined as the time that the cell discharge increased (on cells) or decreased (ofF cells) beyond the range of baseline values. The peak response was the maximum (on cells) or minimum (ofF cells) discharge frequency. 
Two population histograms were calculated by averaging across all on and OFF cells. The population response latency was defined as the time that the average discharge changed from baseline by at least 2 SDs of the baseline discharge rate. The peak population response was the maximum (on cells) or minimum (ofF cells) discharge frequency in the population histogram.

Cellular responses evoked by double laser pulse stimulation. Peristimulus population histograms (bin size: $100 \mathrm{msec}$ ) were used to determine the relative change in cellular activity preceding double laser stimulation, calculated as a ratio of the cellular activity before the first laser pulse to the cellular activity before the second laser pulse. The cellular activity before the first laser pulse was defined as the average discharge frequency for 0.5 sec preceding the onset of the first laser pulse. The cellular activity before the second laser pulse was defined as the average discharge frequency for $0.5 \mathrm{sec}$ preceding the onset of the second laser pulse. For statistical comparisons of the change in cellular activity preceding the two laser pulses, the activity during each of 5 bins $(=0.5 \mathrm{sec})$ preceding each of the pulses was compared.

EMG reactions. The EMG reactions were full wave rectified. The onset of the EMG reaction was visually determined as the point at which the EMG value exceeded the range of EMG values in the prestimulus baseline. When setting the EMG onsets, the investigators could not view the record of cellular discharge. The integrated EMG reaction $0.4-0.9 \mathrm{sec}$ after each laser pulse was calculated and used to compare the relative magnitude of reactions evoked by the first and second laser pulses.

Motor reactions to double laser pulses were calculated as a ratio of the integrated EMG reaction evoked by the second pulse to the integrated EMG reaction evoked by the first pulse $(0.4-0.9 \mathrm{sec}$ after each pulse). A value of 1 indicates that there is neither facilitation nor suppression of the second motor reaction relative to the first reaction, values $>1$ indicate facilitation, and values $<1$ indicate suppression.

\section{Results}

\section{Cellular characterization}

All recorded cells $(n=32)$ were located in the midline raphe or the adjacent nucleus reticularis magnocellularis at or near the level of the facial nucleus (Fig. 1). As detailed in Materials and Methods, cells were physiologically characterized as nonserotonergic by their background discharge pattern. Most cells $(n=24)$ discharged in bursts with a mean $C V_{\text {ISI }}$ of $3.26 \pm 0.52$ and a mean discharge rate of $3.4 \pm 0.8$ spikes per second. A minority of cells $(n=8)$ discharged steadily with a $C V_{\text {ISI }}$ of $<1.0(0.83 \pm 0.06)$ and a mean discharge rate of $15.1 \pm 3.8$ spikes per second.

Cells were either excited $(n=16)$ or inhibited $(n=16)$ by laser stimulation (single pulse or double pulses); these cells were termed ON and OFF cells, respectively (Figs. 2, 3). Of the 32 cells studied, 25 cells were tested for their response to both single and double pulse laser stimulation. Five cells (two on cells, three ofF cells) were tested with single pulse laser stimulation only, and two OFF cells were tested with double pulse laser stimulation only. Of the 30 cells tested for their response to single pulse stimulation, 10 were excited and 13 inhibited ( 10 of 16 oN, 13 of 14 ofF). The remaining cells were identified by their response to double laser pulse stimulation ( six ON cells, three off cells). Nearly all cells that responded to single pulse stimulation responded to double pulse stimulation (17 of 18 tested) consistently, with either excitation $(n=7)$ or inhibition $(n=10)$. One on cell responded to single pulse but was unaffected by double pulse stimulation.

\section{Cellular responses to single laser pulses}

The responses of 10 on cells and 13 off cells to single laser pulse stimulation were analyzed. Among on cells, the mean increase in cell discharge evoked by laser stimulation of the tail was $12.7 \pm$ 2.3 spikes during the initial $2 \mathrm{sec}$ response period. Most on cells ( 8 of 10) were excited by $2 \times \mathrm{SD}_{2} \mathrm{sec}$ for only one $2 \mathrm{sec}$ response period, with the remaining two on cells excited for two response
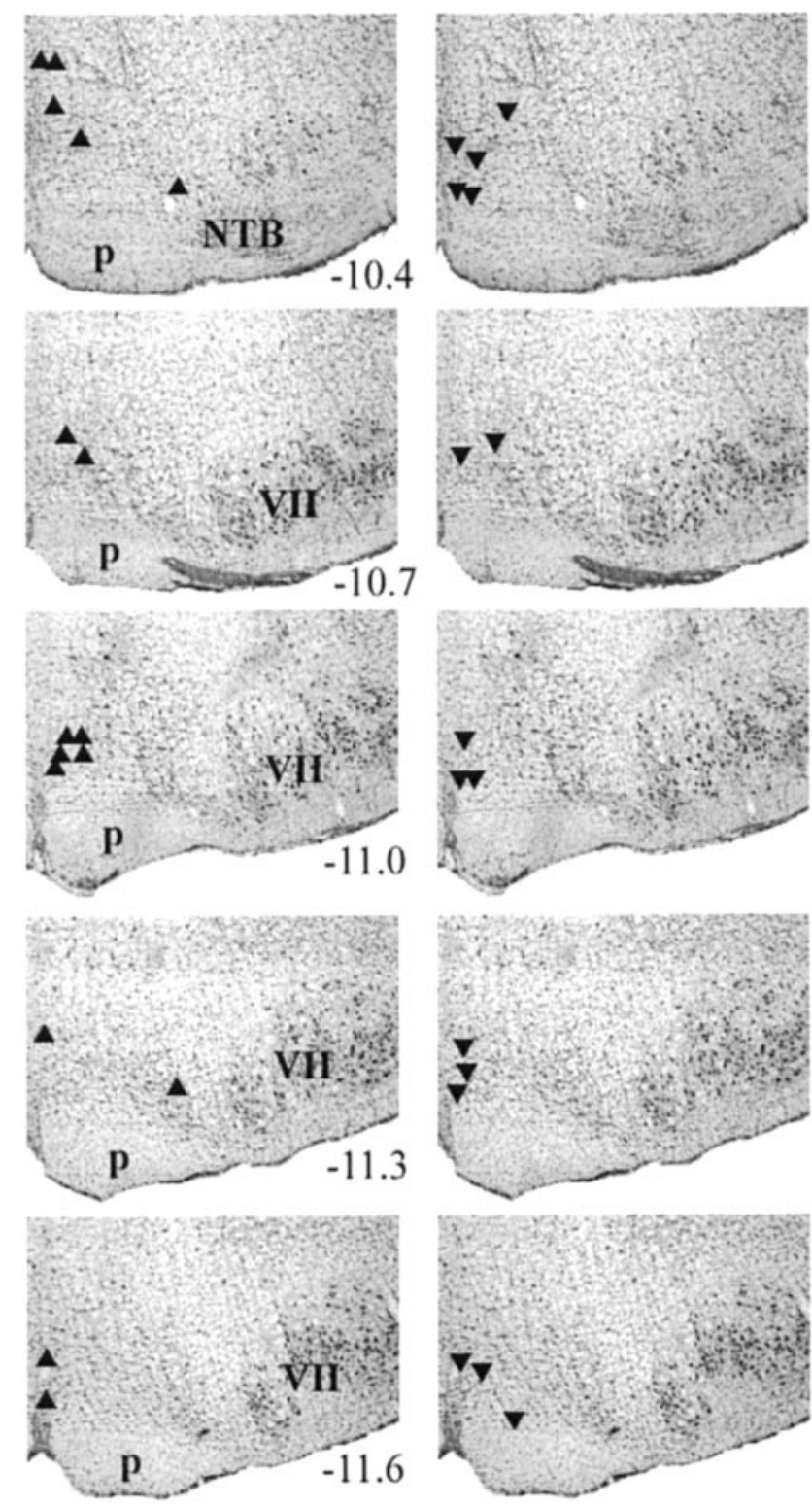

Figure 1. Distribution of recording sites for RM on $(\boldsymbol{\Delta})$ and off $(\boldsymbol{\nabla})$ cells. The numbers indicate the anteroposterior level from bregma for each section. VII, Facial nucleus; NTB, nucleus of the trapezoid body; p, pyramid.

periods. The total response magnitude (total number of spikes during all responsive periods) ranged over more than an order of magnitude from 2.0 to 27.6 spikes and averaged $14.0 \pm 2.6$ spikes. Among OFF cells, the mean decrease in cell discharge evoked by laser stimulation of the tail was $23.9 \pm 3.9$ spikes during the initial $2 \mathrm{sec}$ response period. In contrast to on cells, most off cells ( 9 of 13) were inhibited for more than one response period. The mean duration of off cell inhibition was $3.5 \pm 0.9$ response periods $(=7 \mathrm{sec}$ ), with two off cells inhibited for the entire $20 \mathrm{sec}$ period of analysis. For off cells, the total response ranged over more than an order of magnitude from -24.2 to -638.5 spikes and averaged $-88.4 \pm 46.2$ spikes.

\section{Timing of cellular responses vis à vis EMG reactions to single laser pulses}

The latency of most on ( 7 of 10) and off ( 9 of 13) cell responses to laser heat began in the $50 \mathrm{msec}$ bin after the onset of the motor 
activation (Figs. 2, 3). The remaining three ON cells had response latencies that preceded the motor reaction onset, whereas the remaining four ofF cells had response latencies that followed the motor onset by $>50$ msec. Figures 2 and 3 show exemplary ON and OFF cells that, on average, responded in the $0-50$ msec bin after the motor reaction onset. As shown in Figures $2 B$ and $3 B$, the onset of cell responses was not strictly timed with respect to the onset of EMG activation but varied between individual trials. For the on cell illustrated in Figure $2 B$, the response latency ranged from 22 to $30 \mathrm{msec}$ after the EMG activation began. The start of the pause of the off cell had an even greater range: from $112 \mathrm{msec}$ before to $12 \mathrm{msec}$ after the onset of the motor reaction (Fig. $3 B$ ).

The latencies calculated for the oN and OFF cell populations were in the $50 \mathrm{msec}$ bin preceding the motor reaction, thus differing from those calculated for individual cells (Fig. $4 A, B$ ). This earlier estimate of the population latency than single cell latencies may reflect a subthreshold change in discharge that only becomes apparent after averaging many responses.

No cell response peaked before the onset of the motor reaction. For 6 of 10 oN cells, discharge peaked during the first 50 msec after the onset of the motor reaction. Similarly, the average oN cell population response peaked in the first $50 \mathrm{msec}$ bin after the onset of the motor reaction (Fig. $4 A$ ). Most off cells ( 11 of 13 ) reached their minimum discharge rate within $200 \mathrm{msec}$ of the onset of the motor reaction, whereas the off cell population response reached its minimum 150-200 msec after the start of the motor reaction (Fig. $4 B$ ).

Like the onset of cellular responses, the duration of cellular responses for both ON and OFF cells varied between individual trials (Figs. $2 A, 3 A$ ). As mentioned above, the average ON cell response lasted only $2 \mathrm{sec}$ after a single laser pulse. A similar response duration was reflected in both the population ON cell histogram and the average EMG reaction (Fig. $4 A$ ). A single pulse of laser heat evoked an EMG activation that lasted an average of $220 \mathrm{msec}$ at half-maximal amplitude and was over within $2 \mathrm{sec}$ of its onset (Fig. 4). In contrast, OFF cells responded for an average of $7 \mathrm{sec}$ after a single laser pulse, reflected in the greater duration of the population OFF cell response than the EMG activation (Fig. $4 B$ ).

\section{EMG reactions to double laser pulses}

Because the EMG reaction to each laser pulse was short in duration (see above), the motor reactions to double laser pulses were discrete and could be analyzed separately, even at the shortest interpulse interval of $0.8 \mathrm{sec}$. When double heat pulses were preare shown on the right.
B
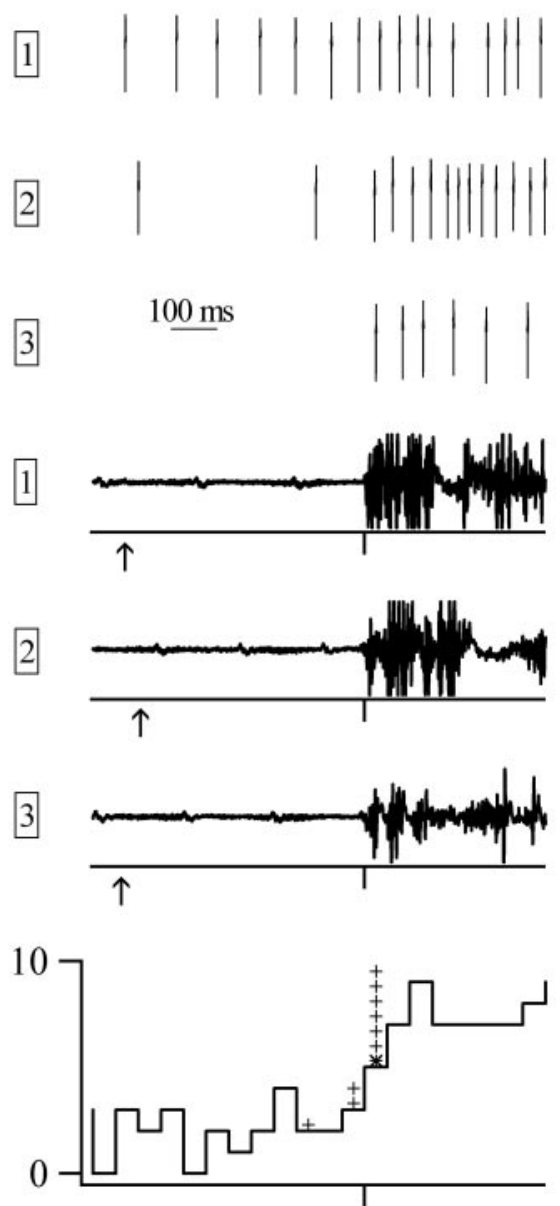
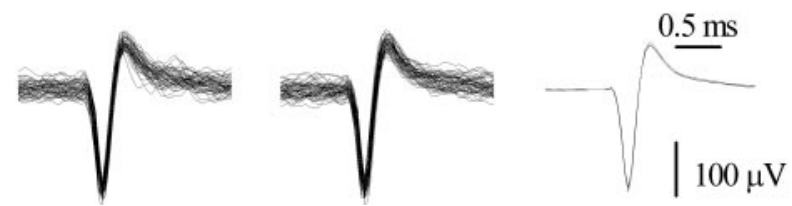

Figure 2. The onset and duration of the response of an on cell to single laser pulse stimulation. $A, B$, Laser stimulation (arrows beneath EMG traces) excites this on cell (top traces) and evokes an EMG reaction (bottom traces). Spikes are illustrated as originally recorded (20 points before threshold crossing and 40 points after, all at $20 \mathrm{kHz}$; see Materials and Methods). The responses recorded during three trials are shown (trial numbers are shown in boxes). The histograms ( 50 msec bins) at the bottom show the average response of the on cell to single laser pulse stimulation across four trials (1 trial is not illustrated here). The asterisk in the right histogram shows the bin during which the response of this cell began. The plus signs show the latencies of the responses of the remaining on cells. All traces are aligned to the start of the motor reaction (tickmarks below EMG traces and histograms). $A$, The duration of the response of the on cell, shown in 10 sec records, varied between trials and was similar to the duration of the EMG activation. $B$, The onset of the burst of the on cell, shown in 1 sec records, varied between trials and was not tightly correlated to the start of the EMG activation. C, Waveforms $(\leq 50)$ from each of the three trials are shown. Averages of all waveforms from each trial

sented $0.8 \mathrm{sec}$ apart, the second motor reaction was significantly larger $(2.8 \pm 0.5$-fold $)$ than the reaction to the first laser pulse (Fig. $5 A$ ) ( $p<0.001$; paired $t$ test). At an interpulse interval of 2.0 $\mathrm{sec}$, the second motor reaction was similarly augmented $(2.5 \pm$ 0.3 -fold) (Fig. $5 B)$ ( $p=0.00$; paired $t$ test). At the longest interpulse interval $(10.0 \mathrm{sec})$, the motor reaction to the second pulse was also facilitated but by only $1.3 \pm 0.1$-fold (Fig. $5 C)(p=$ 0.003 ; paired $t$ test). The facilitatory effects at the two short interpulse intervals $(0.8$ and $2.0 \mathrm{sec})$ were not significantly different from each other, but both of these effects were significantly 
A
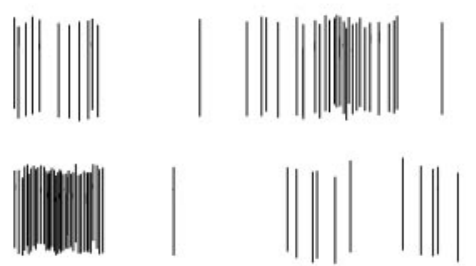

|||||||||||
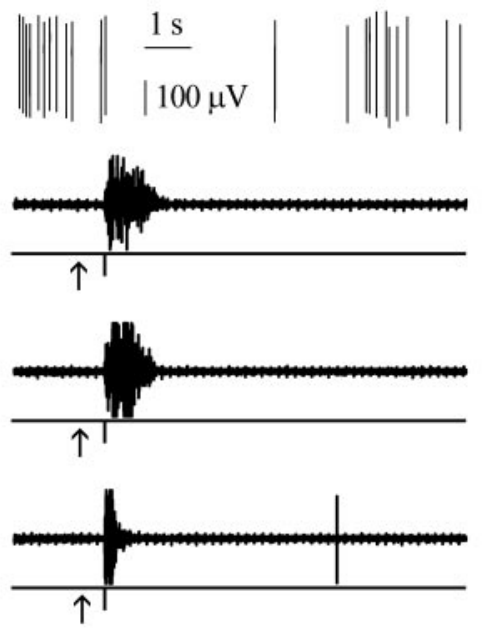

5
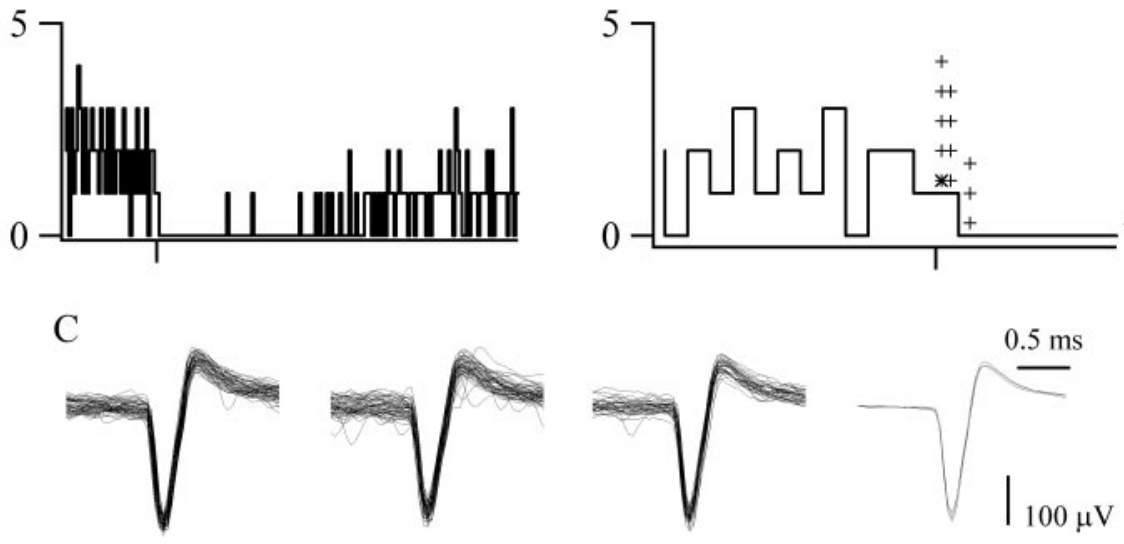

Figure 3. $A, B$, The onset and duration of the response of an off cell to single laser pulse stimulation. Laser stimulation (arrows beneath EMG traces) inhibits this off cell (originally recorded waveforms are shown in the top traces as described for Fig. 2) and evokes an EMG reaction (bottom traces). The responses recorded during three trials are shown (trial numbers are shown in boxes). The histograms ( $50 \mathrm{msec}$ bins) at the bottom show the average response of the off cell to single laser pulse stimulation across four trials (1 trial is not illustrated here). The asterisk in the right histogram shows the bin during which the response of this cell began, and the plus signs show the latencies of the responses of the remaining off cells. All traces are aligned to the start of the motor reaction (tick marks below EMG traces and histograms). $A$, The duration of the response of the off cell, shown in 10 sec records, was always greater than the duration of the EMG activation. $B$, The latency of the pause of the off cell, shown in 1 sec records, varied between trials and was not tightly correlated to the start of the EMG activation. C, Waveforms ( $\leq 50)$ from each of the three trials. Averages of all waveforms from each trial are shown on the right.

greater than the facilitatory effect at the 10.0 sec interpulse interval (Kruskal-Wallis one-Way ANOVA; $p<0.001$ ).

In spinalized rats, the motor reaction to the second laser pulse was never greater than the motor reaction to the first pulse at all three interpulse intervals ( $p>0.05$; paired $t$ tests) (Fig. $5 D-F$ ). The average difference in facilitation of the second motor reaction between intact and spinalized rats was used to estimate the supraspinal contribution to the modulation of motor reactions evoked by repeated noxious stimulation. The estimated values were calculated as $2.3 \times$ at the $0.8 \mathrm{sec}, 2.1 \times$ at the $2.0 \mathrm{sec}$, and $0.8 \times$ at the $10.0 \mathrm{sec}$ interpulse interval.
Relationship between the motor reaction evoked by double laser pulse stimulation and the cellular activity that precedes it

The cellular discharge of both ON and OFF cells before the second laser pulse was different from the discharge preceding the first pulse. ON cells were more active preceding the second laser pulse than the first pulse at all interpulse intervals $(p<0.05$; paired $t$ tests) (Fig. $6 A-C$ ). The mean oN cell discharge was greater by 43 spikes (in $0.5 \mathrm{sec}$ ) at the $0.8 \mathrm{sec}$ interpulse interval, 19 spikes at the 2.0 sec interval, and 9 spikes at the $10.0 \mathrm{sec}$ interval. The increase was significantly larger at the $0.8 \mathrm{sec}$ interpulse interval than at the 2.0 and $10.0 \mathrm{sec}$ interpulse intervals $(p \leq 0.001$; ANOVA; Student-Newman-Keuls). The mean increases in on cell discharges at the 2.0 and $10 \mathrm{sec}$ interpulse intervals were not different.

At all interpulse intervals, OFF cells were less active for the $0.5 \mathrm{sec}$ preceding the second laser pulse than for the corresponding time preceding the first pulse $(p<0.05$; paired $t$ tests) (Fig. $6 D-F$ ). The mean ofF cell discharge was decreased by 49 spikes at the $0.8 \mathrm{sec}$ interpulse interval, 40 spikes at the $2.0 \mathrm{sec}$ interval, and 15 spikes at the $10.0 \mathrm{sec}$ interval. The mean decreases were greater at the 0.8 and $2.0 \mathrm{sec}$ interpulse intervals than at the $10.0 \mathrm{sec}$ interpulse inter$\operatorname{val}(p=0.02$ and 0.03 ; ANOVA; StudentNewman-Keuls). The mean decreases in OFF cell discharge at the 0.8 and $2.0 \mathrm{sec}$ interpulse intervals were not significantly different.

\section{Discussion}

The laser heat-evoked withdrawal reaction

$\mathrm{CO}_{2}$ laser heat stimulation activates nociceptors, evokes a motor withdrawal, and elicits a sensation of pain in humans (Willer et al., 1979; Bromm and Treede, 1983, 1984; Bromm et al., 1984; ArendtNielsen and Bjerring, 1988). The sensation elicited by laser heat stimulation is an early stinging pain followed by a burning pain (Bromm and Treede, 1987). These two perceptual components are likely caused by the activation of $\mathrm{A} \delta$ and $\mathrm{C}$ fiber nociceptors, respectively, by the laser stimulus (Bromm and Treede, 1983, 1984; Bromm et al., 1984). In rats as in humans, laser heat stimulation activates nociceptors, evokes a motor withdrawal, and elicits a response in primary somatosensory cortex (Devor et al., 1982; Kalliomaki et al., 1993; Danneman et al., 1994).

The motor withdrawal evoked by laser heat is analogous to that elicited by slower forms of heat stimulation (Willer et al., 1979; Schouenborg et al., 1992; Bragard et al., 1996; Plaghki et al., 1998) but has the advantage that more is known about its underlying circuitry (Danneman et al., 1994). Initiation of the laser 


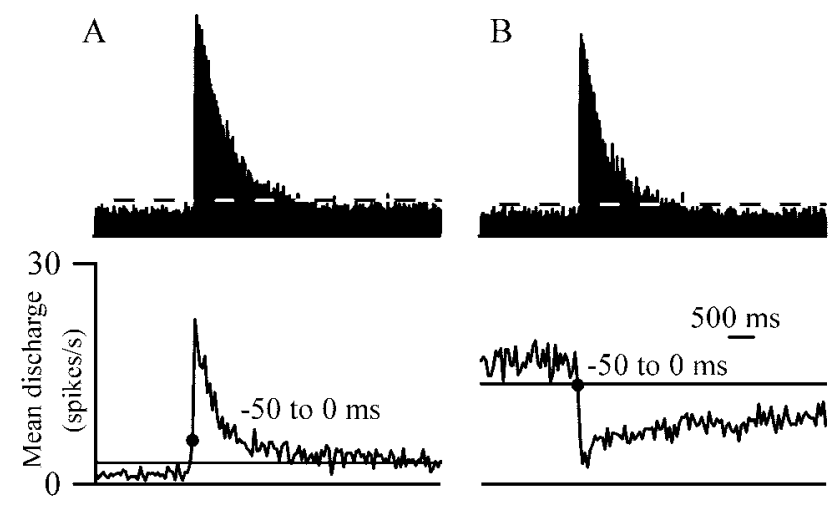

Figure 4. Population histograms of mean motor (top traces) and cellular (bottom traces; bin size: $50 \mathrm{msec}$; aligned to onset of motor withdrawal) responses to single laser pulse stimulation. The lines in each trace show the maximum (EMG, on cell in $A$ ) or minimum (off cell in $B$ ) value observed during the baseline period. $A$, on cells $(n=10)$ began to respond $0-50$ msec before motor withdrawal and peaked within $50 \mathrm{msec}$ after the onset of the motor reaction. $B$, off cells $(n=13)$ began to respond $0-50$ msec before, and peaked $150-200 \mathrm{msec}$ after, the onset of the motor withdrawal. The discharge of both cell types remained different from baseline values ( $6 \mathrm{sec}$ for off cells and $2.5 \mathrm{sec}$ for on cells) for longer than did the motor reactions ( $\leq 2 \mathrm{sec}$ ). The motor records are shown on semi-log plots to best illustrate the duration of the response.

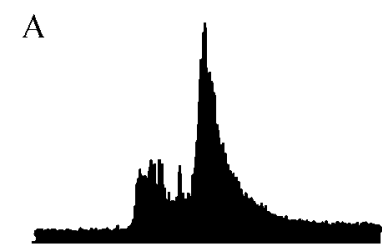

- -

B

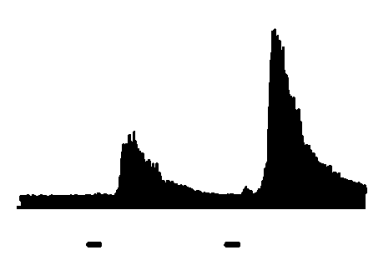

E

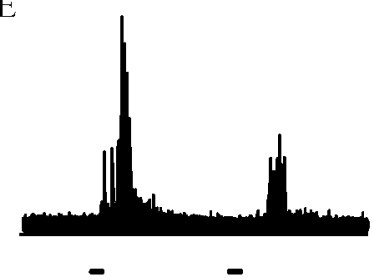

$\mathrm{C}$

F
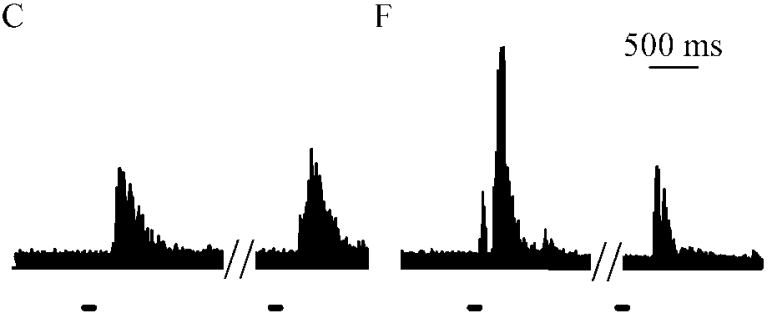

Figure 5. The average EMG reaction to double laser pulse stimulation (lines beneath traces) applied at three different intervals in intact $(A-C)$ and spinalized $(D-F)$ rats. The interstimulus intervals tested were $0.8 \sec (A, D), 2.0 \sec (B, E)$, and $10.0 \sec (C, F)$. $A-C$, In intact rats, the motor reaction to the second laser pulse was facilitated at all interpulse intervals. This facilitation was larger at 0.8 and 2.0 sec interpulse intervals than at the 10.0 sec interpulse interval. $D-F$, In spinalized rats, the motor reaction to the second laser pulse was never greater than that evoked by the first pulse. Scale bar in $F$ applies to all traces.

heat-evoked tail flick depends on activation of $\mathrm{C}$ fiber nociceptors. The central delay, the time between arrival of the nociceptor afferent volley in the dorsal horn and the excitation of the motoneuron, is $\sim 80 \mathrm{msec}$, during which local and supraspinal influences can modulate the start of the motor reaction. Because
A
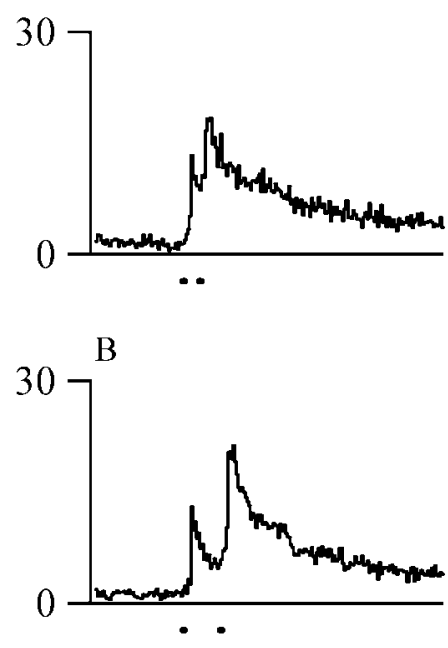

E

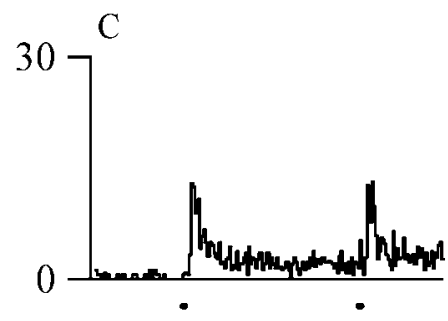

F

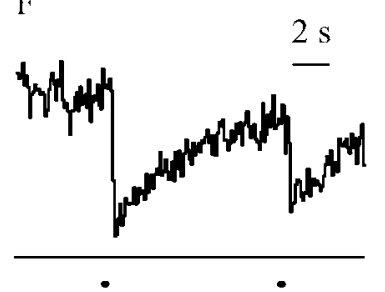

Figure 6. Cellular responses evoked by double pulses of laser heat (lines beneath traces). $A-C$, The mean on cell discharge was greater preceding the second laser pulse than preceding the first pulse at all interpulse intervals. The mean increases were significantly larger at the 0.8 interpulse interval than at the 2.0 or 10.0 sec interpulse intervals. $D-F$, The mean off cell discharge was less preceding the second laser pulse than preceding the first pulse at all interpulse intervals. The mean decreases were significantly larger at the 0.8 and 2.0 sec interpulse intervals than at the 10.0 sec interpulse interval. Scale bar in $F$ applies to all traces.

the motor reaction continues for seconds, modulatory influences may continue to alter its magnitude and duration.

\section{Timing of the RM cellular response}

All off cells and most on cells in RM start to respond to laser heat just after the onset of the evoked motor withdrawal. Because the conduction velocities of oN and off cells range from 5 to $25 \mathrm{~m} / \mathrm{sec}$ (Vanegas et al., 1984) and the distance from RM to the lumbosacral cord is $\sim 125 \mathrm{~mm}$, the shortest time required for RM cell discharge to influence spinal nociceptive transmission is 5-25 msec. Therefore, it is unlikely that RM ON and off cells have a major influence on withdrawal initiation from laser heat. Similarly, the RM cell response to electrical stimulation of the tooth pulp begins after the initiation of the disynaptic withdrawal reflex in cats (Mason et al., 1986). Electrical stimulation of the cat tooth pulp is a nearly pure nociceptive stimulus (Mason et al., 1985) and resembles laser stimulation in its short duration and synchronous activation of afferents.

The above calculations suggest that on and off cells influence dorsal horn circuitry within $100 \mathrm{msec}$ of the start of the motor reaction. Yet it is unlikely that the arrival of on and off cell responses within the spinal cord marks the precise moment that cell discharge begins to influence target neuronal firing. Postsynaptic cells must integrate ON and off cell discharge over a period of time before altering their discharge. This is particularly true because both ON and OFF cells are spontaneously bursting rather than 
silent (Barbaro et al., 1989; Leung and Mason, 1998, 1999), making it unlikely that a postsynaptic cell will be influenced by the sudden occurrence or absence of a single spike.

The population response latency, unlike single cell latencies, occurs in the $50 \mathrm{msec}$ before the tail flick. This is likely attributable to a slight elevation (ON cells) or depression (OFF cells) in the probability of firing just before the tail flick. For instance, if the discharge probability of an on cell increased to a value $<50 \%$ during the $50 \mathrm{msec}$ before the flick, then no additional spikes would occur at this time in most trials. Such a small, subthreshold change in RM discharge probability would not have a major effect on the firing of the postsynaptic cells.

The on cell response to laser heat closely resembles the evoked EMG reaction in time and form (i.e., peaking early and then declining) and may contribute to producing the motor reaction. In support of this idea, the enhanced nociceptive reactions observed during conditions of persistent pain are critically dependent on descending RM on cell discharge (Porreca et al., 2001, 2002). In contrast to the oN cell burst, the ofF cell pause evoked by laser heat is much longer than the evoked EMG reaction. Thus, although the off cell response may contribute to modulating the magnitude and duration of the motor reaction, it is also likely to modulate the preparedness of spinal circuits to ensuing noxious insults. These considerations lead to the idea that changes in ON and OFF cell discharge are likely to manifest effects on spinal neurons during the later portion of the EMG reaction at the very earliest. The influence of the off cell may continue for some time after withdrawal completion.

\section{Augmentation of motor reaction by repeated stimulation}

In intact rats, motor reactions were facilitated by repeated laser heat stimulation, more so at interstimulus intervals of $\leq 2 \mathrm{sec}$ than at an interval of $10 \mathrm{sec}$. Similarly, in humans, the second of two brief heat stimuli applied at interstimulus intervals of 3-7 sec elicits more pain than does the first (Vierck et al., 1997). When electrical shock is used, double stimulation does not consistently evoke facilitation (Arendt-Nielsen et al., 1994, 2000; Gozariu et al., 1997). For instance, repeated electrical stimulation of the sural nerve, at intensities sufficient to activate $C$ fibers, facilitates the late motor reflex at interstimulus intervals of 1-2 sec in rats (Gozariu et al., 1997) but not humans (Arendt-Nielsen et al., 2000). Electrical stimulation differs from thermal stimulation in that it activates all afferent types and is completely synchronous.

Using an approach previously used by several laboratories, motor reactions were tested in unanesthetized, spinalized rats to estimate the supraspinal contribution to the motor facilitation evoked by repeated laser heat stimulation (Stein et al., 1987; Schouenborg et al., 1992; Morgan et al., 1994; Gozariu et al., 1998). In the absence of supraspinal input, there was no motor facilitation to repeated laser stimulation at any interval tested. Thus, the motor facilitation observed in intact rats is dependent on supraspinal input, possibly from RM, and is not caused by temporal summation at the spinal level or by local cutaneous storage of heat. Similarly, temporal summation elicited by repeated heat stimulation is poorly correlated with skin temperature, suggesting that heat storage in the skin is not critical (Vierck et al., 1997).

\section{Cellular mediation of facilitation}

$\mathrm{RM}$ is one of several regions that project to the dorsal horn and modulate somatosensory information (Sandkuhler, 1996; Willis and Westlund, 1997; Porreca et al., 2002). When tail flick is facilitated by previous tooth pulp stimulation, this is accompanied by
Table 1. off cell inactivity allows the on cell to facilitate the motor reaction

\begin{tabular}{|c|c|c|c|}
\hline $\begin{array}{l}\text { Interstimulus } \\
\text { interval (sec) }\end{array}$ & $\begin{array}{l}\text { off cell discharge } \\
\text { (before 2nd } \\
\text { pulse relative to } \\
\text { before 1st pulse) }\end{array}$ & $\begin{array}{l}\text { on cell discharge } \\
\text { (before 2nd } \\
\text { pulse relative to } \\
\text { before 1st pulse) }\end{array}$ & $\begin{array}{l}\text { Predicted motor } \\
\text { reaction } \\
\text { (to } 2 \text { nd pulse relative } \\
\text { to } 1 \text { st pulse) }\end{array}$ \\
\hline 0.8 & $\downarrow \downarrow$ & $\uparrow \uparrow$ & ++ \\
\hline 2.0 & $\downarrow \downarrow$ & $\uparrow$ & + \\
\hline 10.0 & $\downarrow$ & $\uparrow$ & + \\
\hline
\end{tabular}

Magnitude of facilitation is entirely dependent on on cell discharge.

Table 2. off cell discharge alone disinhibits the motor reaction

\begin{tabular}{lll}
\hline & $\begin{array}{l}\text { OFf cell discharge } \\
\text { (before 2nd } \\
\text { pulse relative to } \\
\text { before 1st pulse) }\end{array}$ & $\begin{array}{l}\text { Predicted motor } \\
\text { reaction } \\
\text { (to 2nd pulse relative } \\
\text { interstimulus }\end{array}$ \\
\hline 0.8 & $\downarrow \downarrow$ & ++ \\
2.0 & $\downarrow \downarrow$ & ++ \\
10.0 & $\downarrow$ & +
\end{tabular}

Magnitude of facilitation is entirely dependent on off cell discharge.

Table 3. ofF and on cell discharge together facilitate the motor reaction

\begin{tabular}{llll}
\hline & $\begin{array}{l}\text { Off cell discharge } \\
\text { (before 2nd } \\
\text { pulse relative to } \\
\text { before 1st pulse) }\end{array}$ & $\begin{array}{l}\text { on cell discharge } \\
\text { (before 2nd } \\
\text { pulse relative to } \\
\text { before 1st pulse) }\end{array}$ & $\begin{array}{l}\text { Predicted motor } \\
\text { reaction } \\
\text { (to 2nd pulse relative } \\
\text { to 1st pulse) }\end{array}$ \\
\hline 0.8 & $\downarrow \downarrow$ & $\uparrow \uparrow$ & ++++ \\
2.0 & $\downarrow \downarrow$ & $\uparrow$ & +++ \\
10.0 & $\downarrow$ & $\uparrow$ & ++ \\
\hline
\end{tabular}

Magnitude of facilitation is dependent on both off and on cell discharge.

decreases in the latency of the on cell burst and off cell inactivity (Ramirez and Vanegas, 1989; H. Vanegas, personal communication). In the present study, increases in on cell activity and decreases in OFF cell activity were associated with motor facilitation evoked by double pulses of laser heat. ON cell discharge preceding the second laser pulse was larger at the $0.8 \mathrm{sec}$ interpulse interval than at either the 2 or $10 \mathrm{sec}$ intervals. These increases do not parallel the motor facilitation, which was greater at the two short interpulse intervals than at the longest interval. However, the decreases in off cell discharge mirrored the facilitative changes in motor reactions, with off cell discharge greater at the two short intervals than at the longest interval.

Tables 1, 2, and 3 present three possible models of how ON and OFF cell discharge could produce the observed facilitation of laserevoked motor reactions. First, the decrease in off cell discharge may act as a switch that allows the changes in on cell discharge to facilitate the motor reaction (Table 1). Accordingly, the predicted motor facilitation would be greater at the $0.8 \mathrm{sec}$ interval than at the 2.0 and 10.0 sec intervals. The present data do not support this model. A second possibility is that a decrease in off cell discharge produces a decrease in descending inhibition, resulting in a disinhibition of the motor reaction (Table 2). Although our results support this model in terms of the predicted motor facilitation, it is unlikely that OFF cells alone play a role in the motor facilitation. We favor the idea that ON and OFF cells act together to modulate the magnitude of a motor reaction (Table 3). ON and off cells have the appropriate physiology to mediate the motor facilitation that is observed to repeated stimulation. OfF cells are excited by analgesic doses of opioids and are likely to act as the nociceptiveinhibitory output neuron of RM (Basbaum and Fields, 1984; Fields et al., 1991; Porreca et al., 2002). In contrast, ON cells are excited by peripheral noxious stimulation, inhibited by opioids, 
and have recently been implicated as critical mediators of nociceptive reactions (Porreca et al., 2002). Thus, on cell discharge and OFF cell silence, as occurs after noxious stimulation, would be expected to enhance the reaction to further noxious stimulation. By thus augmenting the reaction to sustained or repeated insults, such as those that occur during an attack, ON and OFF cells serve an important protective function.

\section{References}

Arendt-Nielsen L, Bjerring P (1988) Reaction times to painless and painful $\mathrm{CO}_{2}$ and argon laser stimulation. Eur J Appl Physiol 58:266-273.

Arendt-Nielsen L, Brennum J, Sindrup S, Bak P (1994) Electrophysiological and psychophysical quantification of temporal summation in the human nociceptive system. Eur J Appl Physiol 68:266-273.

Arendt-Nielsen L, Sonnenborg FA, Andersen OK (2000) Facilitation of the withdrawal reflex by repeated transcutaneous electrical stimulation: an experimental study on central integration in humans. Eur J Appl Physiol 81:165-173.

Barbaro NM, Heinricher MM, Fields HL (1989) Putative nociceptive modulatory neurons in the rostral ventromedial medulla of the rat display highly correlated firing patterns. Somatosens Mot Res 6:413-425.

Basbaum AI, Fields HL (1984) Endogenous pain control systems: brainstem spinal pathways and endorphin circuitry. Annu Rev Neurosci 7:309-338.

Bragard D, Chen AC, Plaghki L (1996) Direct isolation of ultra-late (Cfibre) evoked brain potentials by $\mathrm{CO}_{2}$ laser stimulation of tiny cutaneous surface areas in man. Neurosci Lett 209:81-84.

Bromm B, Treede RD (1983) $\mathrm{CO}_{2}$ laser radiant heat pulses activate C nociceptors in man. Pflügers Arch 399:155-156.

Bromm B, Treede RD (1984) Nerve fibre discharges, cerebral potentials and sensations induced by $\mathrm{CO}_{2}$ laser stimulation. Hum Neurobiol 3:33-40.

Bromm B, Treede RD (1987) Human cerebral potentials evoked by $\mathrm{CO}_{2}$ laser stimuli causing pain. Exp Brain Res 67:153-162.

Bromm B, Jahnke MT, Treede RD (1984) Responses of human cutaneous afferents to $\mathrm{CO}_{2}$ laser stimuli causing pain. Exp Brain Res 55:158-166.

Carstens E, Wilson C (1993) Rat tail flick reflex: magnitude measurement of stimulus-response function, suppression by morphine and habituation. J Neurophysiol 70:630-639.

Danneman PJ, Kiritsy-Roy JA, Morrow TJ, Casey KL (1994) Central delay of the laser-activated rat tail-flick reflex. Pain 58:39-44.

Devor M, Carmon A, Frostig R (1982) Primary afferent and spinal sensory neurons that respond to brief pulses of intense infrared laser radiation: a preliminary survey in rats. Exp Neurol 76:483-494.

Fields HL, Bry J, Hentall I, Zorman G (1983) The activity of neurons in the rostral medulla of the rat during withdrawal from noxious heat. J Neurosci 3:2545-2552.

Fields HL, Heinricher MM, Mason P (1991) Neurotransmitters in nociceptive modulatory circuits. Annu Rev Neurosci 14:219-245.

Gao K, Mason P (2000) Serotonergic raphe magnus cells that respond to noxious tail heat are not ON or OFF cells. J Neurophysiol 84:1719-1725.

Gozariu M, Bragard D, Willer JC, Le Bars D (1997) Temporal summation of C-fiber afferent inputs: competition between facilitatory and inhibitory effects on C-fiber reflex in the rat. J Neurophysiol 78:3165-3179.

Gozariu M, Bouhassira D, Willer JC, Le Bars D (1998) The influence of temporal summation on a C-fibre reflex in the rat: effects of lesions in the rostral ventromedial medulla (RVM). Brain Res 792:168-172.

Grossman ML, Basbaum AI, Fields HL (1982) Afferent and efferent connections of the rat tail flick reflex (a model used to analyze pain control mechanisms). J Comp Neurol 206:9-16.

Haimi-Cohen R, Cohen A, Carmon A (1983) A model for the temperature distribution in skin noxiously stimulated by a brief pulse of $\mathrm{CO}_{2}$ laser radiation. J Neurosci Methods 8:127-137.

Kalliomaki J, Weng HR, Nilsson HJ, Schouenborg J (1993) Nociceptive C fibre input to the primary somatosensory cortex (SI). A field potential study in the rat. Brain Res 622:262-270.
Le Bars D, Gozariu M, Cadden SW (2001) Animal models of nociception. Pharmacol Rev 53:597-652.

Leung CG, Mason P (1998) Physiological survey of medullary raphe and magnocellular reticular neurons in the anesthetized rat. J Neurophysiol 80:1630-1646.

Leung CG, Mason P (1999) Physiological properties of raphe magnus neurons during sleep and waking. J Neurophysiol 81:584-595.

Li YW, Bayliss DA (1998) Electrophysical properties, synaptic transmission and neuromodulation in serotonergic caudal raphe neurons. Clin Exp Pharmacol Physiol 25:468-473.

Mason P (1997) Physiological identification of pontomedullary serotonergic neurons in the rat. J Neurophysiol 77:1087-1098.

Mason P (2001) Contributions of the medullary raphe and ventromedial reticular region to pain modulation and other homeostatic functions. Annu Rev Neurosci 24:737-777.

Mason P, Gao K (1998) Raphe magnus serotonergic neurons tonically modulate nociceptive transmission. Pain Forum 7:143-150.

Mason P, Strassman A, Maciewicz R (1985) Is the jaw-opening reflex a valid model of pain? Brain Res 357:137-146.

Mason P, Strassman A, Maciewicz R (1986) Intracellular responses of raphe magnus neurons during the jaw-opening reflex evoked by tooth pulp stimulation. Brain Res 379:232-241.

Mor J, Carmon A (1975) Laser emitted radiant heat for pain research. Pain 1:233-237.

Morgan MM, Heinricher MM, Fields HL (1994) Inhibition and facilitation of different nocifensor reflexes by spatially remote noxious stimuli. J Neurophysiol 72:1152-1160.

Plaghki L, Bragard D, Le Bars D, Willer JC, Godfraind JM (1998) Facilitation of a nociceptive flexion reflex in man by nonnoxious radiant heat produced by a laser. J Neurophysiol 79:2557-2567.

Porreca F, Burgess SE, Gardell LR, Vanderah TW, Malan TP Jr, Ossipov MH, Lappi DA, Lai J (2001) Inhibition of neuropathic pain by selective ablation of brainstem medullary cells expressing the micro-opioid receptor. J Neurosci 21:5281-5288.

Porreca F, Ossipov MH, Gebhart GF (2002) Chronic pain and medullary descending facilitation. Trends Neurosci 25:319-325.

Potrebic SB, Fields HL, Mason P (1994) Serotonin immunoreactivity is contained in one physiological cell class in the rat rostral ventromedial medulla. J Neurosci 14:1655-1665.

Ramirez F, Vanegas H (1989) Tooth pulp stimulation advances both medullary off-cell pause and tail flick. Neurosci Lett 100:153-156.

Sandkuhler J (1996) The organization and function of endogenous antinociceptive systems. Prog Neurobiol 50:49-81.

Sandkuhler J, Gebhart GF (1984) Relative contributions of the nucleus raphe magnus and adjacent medullary reticular formation to the inhibition by stimulation in the periaqueductal gray of a spinal nociceptive reflex in the pentobarbital-anesthetized rat. Brain Res 305:77-87.

Schouenborg J, Holmberg H, Weng HR (1992) Functional organization of the nociceptive withdrawal reflexes. II. Changes of excitability and receptive fields after spinalization in the rat. Exp Brain Res 90:469-478.

Stein C, Morgan MM, Liebeskind JC (1987) Barbiturate-induced inhibition of a spinal nociceptive reflex: role of GABA mechanisms and descending modulation. Brain Res 407:307-311.

Vanegas H, Barbaro NM, Fields HL (1984) Tail-flick related activity in medullospinal neurons. Brain Res 321:135-141.

Vierck Jr CJ, Cannon RL, Fry G, Maixner W, Whitsel BL (1997) Characteristics of temporal summation of second pain sensations elicited by brief contact of glabrous skin by a preheated thermode. J Neurophysiol 78:992-1002.

Wang W, Tiwari JK, Bradley SR, Zaykin RV, Richerson GB (2001) Acidosisstimulated neurons of the medullary raphe are serotonergic. J Neurophysiol 85:2224-2235.

Willer JC, Boureau F, Berny J (1979) Nociceptive flexion reflexes elicited by noxious laser radiant heat in man. Pain 7:15-20.

Willis WD, Westlund KN (1997) Neuroanatomy of the pain system and of the pathways that modulate pain. J Clin Neurophysiol 14:2-31. 